\title{
Response Patterns of Vegetation Phenology along Urban-Rural Gradients in Urban Areas of Different Sizes
}

\author{
Xue Luo, ${ }^{1}$ Yuqing Zhang $\mathbb{D}{ }^{1}{ }^{1}$ and Dongqi Sun $\mathbb{D}^{2}$ \\ ${ }^{1}$ Human Settlements Research Center, Liaoning Normal University, Dalian 116029, China \\ ${ }^{2}$ Key Laboratory of Regional Sustainable Development Modeling, \\ Institute of Geographic Sciences and Natural Resources Research, CAS, Beijing 100101, China \\ Correspondence should be addressed to Yuqing Zhang; zhangyuqing@lnnu.edu.cn and Dongqi Sun; sundq@igsnrr.ac.cn
}

Received 4 April 2020; Revised 12 May 2020; Accepted 23 May 2020; Published 20 June 2020

Guest Editor: Jianhong Xia

Copyright (c) 2020 Xue Luo et al. This is an open access article distributed under the Creative Commons Attribution License, which permits unrestricted use, distribution, and reproduction in any medium, provided the original work is properly cited.

\begin{abstract}
On the basis of MODIS Enhanced Vegetation Index time series data and multisource data, such as nighttime light data and China City Statistical Yearbook data, we investigated the differences in vegetation phenology along urban-rural gradients in urban areas of different sizes between coastal and inland cities in Liaoning Province, China. The results showed that the following: (1) the iterative extraction of urban built-up areas using the threshold method based on nighttime light data combined with the definition of urban built-up areas had high accuracy. (2) Additionally, we found that the start of the growing season (SOS) in Liaoning Province occurred between day 100 and day 180, while the end of the growing season (EOS) occurred between days 260 and 330. The difference in the SOS between coastal cities (i.e., Dalian, Yingkou, Panjin, Jinzhou, Huludao, and Dandong) and inland cities (i.e., Chaoyang, Fuxin, Tieling, Shenyang, Fushun, Liaoyang, Benxi, and Anshan) was 1.70 days. However, the difference in the EOS was more significant, i.e., the EOS in coastal cities occurred 4.47 days later than that in the inland cities. (3) In urban areas of different sizes, the $\triangle \mathrm{SOS}$ and $\triangle \mathrm{EOS}$ of inland cities had negative correlations with urban size. Specifically, when the urban size increased 10-fold, the $\triangle \mathrm{SOS}$ and $\triangle \mathrm{EOS}$ advanced by 10.03 and 5.71 days, respectively. In contrast, the $\Delta \mathrm{SOS}$ and $\Delta \mathrm{EOS}$ of coastal cities had positive and negative correlations with the urban size, respectively. Specifically, when urban size increased 10 -fold, $\Delta S O S$ was delayed by 11.29 days while EOS was advanced by 8.83 days.
\end{abstract}

\section{Introduction}

Vegetation phenology refers to cyclic seasonal phenomena such as vegetation growth and other seasonal changes. Phenology can serve as a significant indicator of change in the climate and in ecological environments as well as an important parameter with respect to global changes [1-3]. The city is an open, large-scale, and complex system [4-6]. Urbanization involves the transformation of human production and lifestyle activities from a rural to an urban setting, which can lead to changes in species richness, biological homogenization characteristics, climatic environments, land surface temperatures, water quality, urban ventilation, and $\mathrm{CO}_{2}$ emissions [7-15]. Recently, with the progression of global urbanization, problems associated with the urban ecological environment have become particularly important. Therefore, examinations of the influence that urbanization has on vegetation phenology are crucial when attempting to understand the changes in ecological environments caused by urbanization.

With rapid advances in remote sensing technology, remote sensing data have become a vital tool for large-scale vegetation phenology extractions due to characteristics such as wide coverage extents and extended time series [16]. Current studies on vegetation phenology based on remote sensing technology have focused on changes in vegetation indicated by changes in vegetation indices (Normalized Difference Vegetation Index (NDVI), Enhanced Vegetation Index (EVI), and Leaf Area Index (LAI)); such studies have examined the patterns of spatiotemporal change during the vegetation growth season, their relationships with climate change and urbanization, differences in vegetation phenology among various vegetation 
types, and vegetation productivity trends [17-22]. Studies on the influence of urbanization on vegetation phenology have been predominantly based at the city scale. We used a city or several cities in a region as the research subjects to examine the differences in vegetation phenology along urban-rural gradients. Typically, urban areas have an earlier start of the growing season (SOS) and later end of the growing season (EOS) than rural areas. Earlier work [23] investigated large cities in the United States where the growing season in urban areas lasted significantly longer than in rural areas. Urbanization causes the urban land surface temperature to be higher than the rural land surface temperature, and the urban heat island effect influences vegetation phenology with an exponential function. Zhou et al. [24] also found that an increase in the land surface temperatures in 32 major Chinese cities has led to an earlier SOS and delayed EOS. Other factors such as precipitation, sunshine, vegetation types, climate zone, and topography can affect the vegetation phenology as well [25-29].

The phrase "built-up area" refers to urban areas that are composed of developed land and land under construction within administrative divisions of a city; these areas typically contain municipal utilities and public facilities. The Notice on Adjusting Classification Standards of Urban Size (http:// www.gov.cn/) clearly stipulates that cities be classified into five categories and seven grades in line with urban size classification standards, which are based on the statistical caliber of the resident population in urban areas. However, due to factors such as population mobility, classifying urban sizes according to the population standard is somewhat inaccurate [30]. The extent of built-up areas, as a representation of urban size, has been widely applied to classifications [31, 32]. Different urban sizes can have varying effects on vegetation phenology. For example, a previous study [33] investigated more than 4,500 city clusters of different sizes in the U.S.A., and the results revealed that the SOS advanced by 1.3 days and the EOS was delayed by 2.4 days with a 10 -fold increase in urban size.

The city is the primary target of current research into differences in vegetation phenology along urban-rural gradients, for which there is a lack of comparative studies on coastal and inland cities that have different urban sizes. In this study, we used the Liaoning Province in China as the research subject. On the basis of MODIS EVI time series data and multisource data such as nighttime light data, China City Statistical Yearbook data, and land use data, we investigated the regularity of variations in the vegetation phenology along urban-rural gradients in urban areas of different sizes between coastal and inland cities, so as to quantify the response patterns of vegetation phenology to urbanization. We performed the following analyses: first, we obtained the range of urban built-up areas by using nighttime light data and verified the accuracy of the results; next, we examined the spatial distribution characteristics of vegetation phenology in Liaoning Province; and lastly, we explored the differences in vegetation phenology along urban-rural gradients in differently sized urban areas between coastal and inland cities to reveal the response patterns that vegetation phenology has to urbanization.

\section{Data and Methods}

2.1. Study Area. Liaoning Province (Figure 1) is located in the southern area of Northeast China $\left(38^{\circ} 43^{\prime}-43^{\circ} 26^{\prime} \mathrm{N}\right.$ and $\left.118^{\circ} 53^{\prime}-125^{\circ} 46^{\prime} \mathrm{E}\right)$. Liaoning is the northernmost coastal province in China, and it includes two subprovincial cities (Shenyang and Dalian) and 12 prefecture-level cities (i.e., Yingkou, Panjin, Jinzhou, Huludao, Dandong, Chaoyang, Fuxin, Tieling, Fushun, Liaoyang, Benxi, and Anshan). Liaoning Province has a temperate monsoon climate, with long winters, short summers, and four distinct seasons. Since the 2003 proposal in the national strategy to revitalize old industrial bases in Northeast China, urbanization in Liaoning Province has progressed rapidly. Therefore, this is a representative area for the examination of spatiotemporal changes in vegetation phenology along urban-rural gradients in different urban areas.

2.2. Data Processing. In consideration of the research requirements and data availability, the data included in the present study were remote sensing imagery data and China City Statistical Yearbook data, as detailed in Table 1. Data processing consisted of the following methods: (1) batch processing of remote sensing data, i.e., splicing, projection, resampling, and cropping by administrative division and (2) summary and analysis of statistical data using the built-up area data in the China City Statistical Yearbook.

\subsection{Research Methods}

2.3.1. Extraction of Urban Built-Up Areas Using the Threshold Method. To cover the time range of this study (2001-2018), Defense Meteorological Satellite Program Operational Linescan System (DMSP/OLS) and National Polar Orbiting Partnership-Visible Infrared Imaging Radiometer Suite (NPP-VIIRS) images were used as the data sources for the built-up areas. Considering the continuity of nighttime light data and the differences in the sensors between the DMSP/OLS and NPP-VIIRS images, we integrated these two data types and extracted the boundaries of the urban built-up areas with reference to the built-up areas reported in the China City Statistical Yearbook [34-36]. The specific method was as follows:

(1) The DMSP/OLS and NPP-VIIRS data were preprocessed using techniques such as splicing, projection, resampling, and cropping.

(2) The NPP-VIIRS data were processed via negative elimination and average annual synthesis to obtain the annual NPP-VIIRS nighttime light data in 2013, 2015, and 2018.

(3) With the DMSP/OLS and NPP-VIIRS data for 2013, DMSP data with a digital number (DN) value between 0 and 50 were used as a mask to calculate the mean of the corresponding areas in the NPP-VIIRS data. These areas were used as constant target areas to fit the NPPVIIRS data in 2013. The fitted results were used to correct the NPP-VIIRS data in 2015 and 2018. 


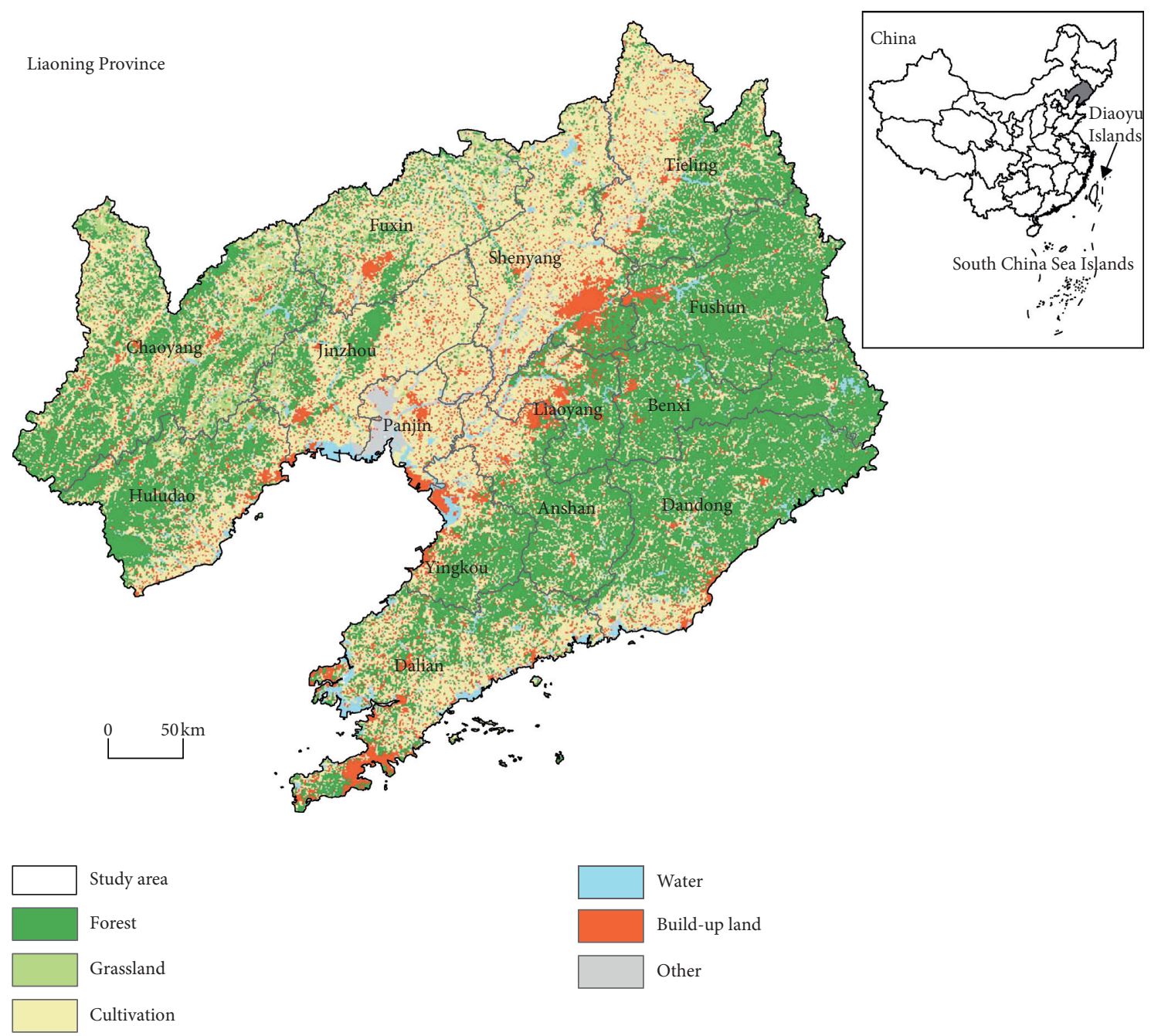

Figure 1: The location of the study area and land use types in 2018.

TABle 1: Data sources and descriptions.

\begin{tabular}{|c|c|c|c|c|}
\hline Data type & Data features & Data sources & Year & Data processing \\
\hline MOD13Q1 & $250 \mathrm{~m} / 16 \mathrm{~d}$ & https://lpdaac.usgs.gov/ & $\begin{array}{c}\text { 2001, 2005, 2010, } \\
2015,2018\end{array}$ & Batch processing \\
\hline DMSP & $1000 \mathrm{~m}$ & https://ngdc.noaa.gov/ & $\begin{array}{c}2001,2005,2010, \\
2013\end{array}$ & Batch processing \\
\hline VIIRS-NPP & $500 \mathrm{~m}$ & https://ngdc.noaa.gov/ & 2013, 2015, 2018 & $\begin{array}{l}\text { Batch processing and } \\
\text { correction }\end{array}$ \\
\hline $\begin{array}{l}\text { China's land use/cover } \\
\text { datasets }\end{array}$ & $100 \mathrm{~m}$ & http://www.resdc.cn/ & $\begin{array}{c}2001,2005,2010 \\
2015,2018\end{array}$ & $\begin{array}{c}\text { Differentiate land use } \\
\text { types }\end{array}$ \\
\hline $\begin{array}{l}\text { Administrative divisions } \\
\text { data }\end{array}$ & $\begin{array}{l}\text { Regional } \\
\text { boundaries }\end{array}$ & $\begin{array}{l}\text { National Catalogue Service for } \\
\text { Geographic Information }\end{array}$ & 2017 & $\begin{array}{c}\text { Extract administrative } \\
\text { divisions }\end{array}$ \\
\hline $\begin{array}{l}\text { China City Statistical } \\
\text { Yearbook }\end{array}$ & Text format & National Bureau of Statistics of China & $\begin{array}{c}2001,2005,2010 \\
2015,2018\end{array}$ & Summary and analysis \\
\hline
\end{tabular}

(4) Extremely high and unstable values were removed from the corrected NPP-VIIRS data to obtain a continuous sequence of nighttime light remote sensing images.

(5) With reference to the statistical area of urban built-up areas in Liaoning Province, the threshold method was applied to iteratively extract the urban built-up areas.
2.3.2. Extraction of Vegetation Phenology Using the Amplitude Method. The Savitzky-Golay (S-G) filter can describe complex and small changes in NDVI time series data and suppress noise such as that due to cloud pollution and atmospheric changes [37, 38]. MODIS EVI is the development and continuation of MODIS NDVI, and we used the S-G filter to smooth the MODIS EVI time series data. The 
methods to obtain vegetation phenology through TIMESAT included the threshold and amplitude methods. We used the amplitude method to extract the vegetation phenology with an amplitude of $30 \%$. As human activity results in abnormal values for vegetation phenology, we set the effective range of the SOS and EOS to days 50-180 and days 240-330, respectively, to ensure data accuracy $[39,40]$.

\subsubsection{Differences in Vegetation Phenology along Urban-Rural} Gradients. We calculated the mean SOS and EOS in urban and rural areas and compared, step by step, the differences in vegetation phenology along urban-rural gradients by using the following expression:

$$
\Delta \mathrm{SOS} i=\mathrm{SOS} u b-\mathrm{SOS} r i
$$

where SOSub and SOSri represent the mean SOS of the urban areas and $i^{\text {th }}$ buffer zones, respectively, and $\Delta S O S i$ represents the differences in the SOS along the urban-rural gradients [24]. When negative, the SOS of a rural area is later than that of an urban area. When positive, the SOS of a rural area is earlier than that of an urban area. The method to calculate the differences in the EOS along urban-rural gradients is identical to that of the SOS.

\section{Results}

3.1. Extraction Results for Built-Up Areas. The threshold method was applied to iteratively extract the built-up areas of 14 cities in Liaoning Province in 2001, 2005, 2010, 2015, and 2018. In addition, the intersection of built-up areas in each year was used as the urban area. With the urban area as the center, 10 buffer zones with a diameter of $1 \mathrm{~km}$ were established as the rural areas surrounding the urban centers (Figure 2). For the spatial distribution characteristics, the built-up area in Shenyang was the largest. Built-up areas included a variety of land use types, such as urban construction land, water bodies, and parks, which demonstrated evident continuity and, therefore, were consistent with the definition of an urban built-up area. Table 2 lists the error rates associated with the extraction of urban built-up areas in 2001, 2005, 2010, 2015, and 2018, which were below $7 \%$. Referring to previous results and research needs [41, 42], these data conform to the accuracy requirements of our study.

3.2. Extraction Results for Vegetation Phenology. We examined the spatial distribution characteristics of the vegetation phenology in Liaoning Province by calculating the mean SOS and EOS in 2001, 2005, 2010, 2015, and 2018 (Figure 3). In Liaoning, the SOS occurred during days 100-180, with a mean of 147.28 days, while the EOS occurred during days 260-330, with a mean of 290.12 days. Based on the heterogeneity of the spatial patterns, the SOS in eastern and part of western Liaoning was earlier, i.e., it occurred during days 110-130; in contrast, the SOS in central and part of western Liaoning, as well as northern Dalian was later than that in eastern Liaoning, i.e., it mainly occurred during days 150-180. The distribution difference in the EOS was smaller than that in the SOS. The EOS in eastern and central Liaoning as well as part of Dalian occurred during days 300-330, later than that in western and part of central Liaoning, which mainly occurred during days 270-290. The difference in the SOS was minor between coastal cities and inland cities, as the mean SOS of the former was 146.22 days and 147.92 days for the latter. In contrast, the difference in the EOS was significant between coastal and inland cities, where the mean EOS of the former was 292.89 days while that of the latter was 288.42 days.

\subsection{Differences in Vegetation Phenology along Urban-Rural} Gradients in Variously Sized Urban Areas. In contrast with rural areas, urban areas had an earlier SOS and later EOS (Figure 4). With an increase in distance from an urban area, the SOS of all cities showed a gradually delaying trend, especially in Shenyang and Yingkou, in which the SOS was delayed by 36.53 days and 35.55 days, respectively. The EOS exhibited a gradually advancing trend with an increasing distance from the urban area, especially in Jinzhou, Chaoyang, and Fuxin, in which the EOS advanced by 18.65, 17.99 , and 17.35 days, respectively. The degree of difference in the SOS and EOS along the urban-rural gradients varied appreciably between the coastal and inland cities. The difference in the SOS along urban-rural gradients of coastal cities was slightly smaller than that of inland cities. Specifically, with the increase in distance from an urban area, the mean delay of the SOS in coastal cities was 20.40 days while that in inland cities was 21.25 days. The difference in the EOS along urban-rural gradients between the coastal and inland cities was significantly smaller than the difference in the SOS. The difference in the EOS along the urban-rural gradients of the coastal cities was smaller than that of the inland cities. With the increase in the distance from the urban area, the mean advance in the EOS for the coastal cities was 10.48 days while that in the inland cities was 13.33 days.

The difference in vegetation phenology along urbanrural gradients in various sized urban areas changed significantly between the coastal and inland cities. The builtup areas, representing various urban sizes, are plotted on the $x$-axis, whereas the difference in phenology between the urban and rural areas is plotted on the $y$-axis in Figure 5. Correlation models between urban size and difference in phenology were established to represent the influence that different urbanization processes have on the vegetation phenology in coastal and inland cities. There was a significant negative correlation between the $\triangle \mathrm{SOS}$ and urban size in inland cities, i.e., a larger urban size was associated with a larger $\triangle$ SOS. When the urban size increased 10 -fold, the $\triangle \mathrm{SOS}$ advanced by 10.03 days. In contrast, there was a negative correlation between the $\triangle \mathrm{EOS}$ and urban size. When the urban size increased 10-fold, the $\triangle E O S$ advanced by 5.71 days. Correlations between the difference in the vegetation phenology along urban-rural gradients and urban size in coastal cities differed from those in the inland cities. In coastal cities, there was a positive correlation 


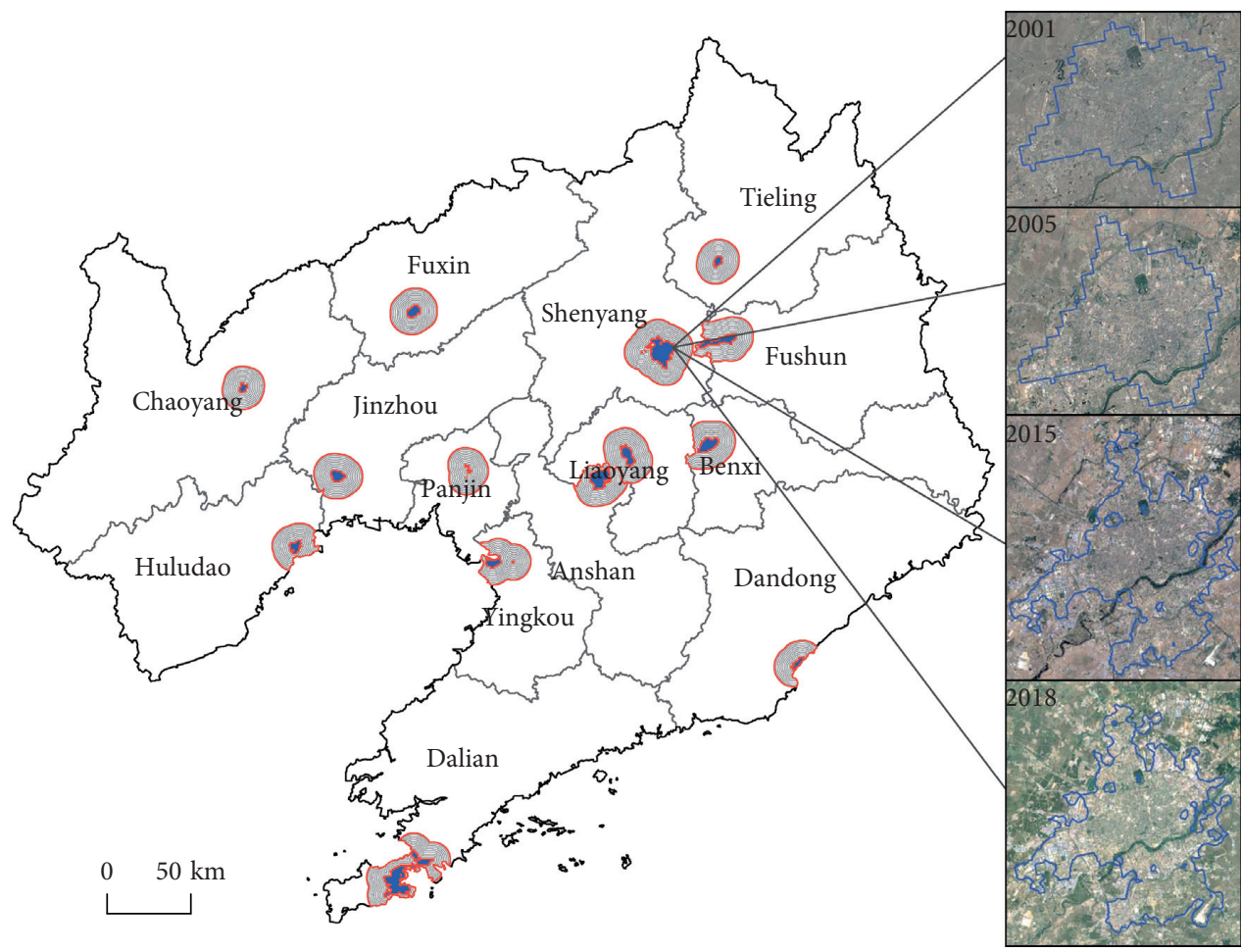

Urban areas

Rural areas

Buffers

FIGURE 2: Results for urban areas and rural areas (example of Shenyang to show the extraction results for urban built-up areas year by year).

TABLe 2: Accuracy validation results for the built-up areas.

\begin{tabular}{lcccc}
\hline & 2001 & 2005 & 2010 & 2015 \\
\hline Nighttime light data $\left(\mathrm{km}^{2}\right)$ & 1298.51 & 1415.00 & 1646.00 & 1953.00 \\
China City Statistical Yearbook $\left(\mathrm{km}^{2}\right)$ & 1270.28 & 1473.62 & 1542.91 & 2219.00 \\
Error $\left(\mathrm{km}^{2}\right)$ & 28.23 & -58.62 & 103.09 & 17.91 \\
Error rate $(\%)$ & 2.17 & -4.14 & 6.26 & 2192.94 \\
\hline
\end{tabular}

between the $\triangle$ SOS and urban size, i.e., a larger urban size was associated with a smaller $\triangle$ SOS. When the urban size increased by 10 -fold, the $\Delta$ SOS was delayed by 11.29 days. In contrast, there was a negative correlation between $\triangle \mathrm{EOS}$ and urban size. When the urban size increased by 10 -fold, the $\triangle \mathrm{EOS}$ advanced by 8.83 days.

\section{Discussion}

4.1. Reasons for the Differences in Vegetation Phenology between Coastal Cities and Inland Cities. Differences in climate zones and vegetation types can affect vegetation phenology [43-47]. According to climate zone results from the Data Center for Resources and Environmental Sciences of the Chinese Academy of Sciences, 14 of the cities in Liaoning Province are located within five different climate zones. Based on the statistical results, different climate zones have different SOS and EOS times (Figure 6(a)). As the Sanjiang-Changbai region contains more forests, it had an earlier SOS and later
EOS. Different climate zones led to differences in urban vegetation phenology (Figure 6(b)). As vegetation types varied in different regions, the mean phenology of agricultural land (paddy fields and dry land), forestland (woodland, shrub land, sparse woodland, and other woodlands), and grassland (highcover, midcover, and low-cover grassland) were calculated using classification criteria based on remote sensing data for land use (Table 3). The results showed that the SOS of forestland was earlier than that of agricultural land and grassland while the EOS was later, which was a result closely related to the comprehensive influence that human and climatic factors have on agricultural land [48].

These differences in climate led to differences in the vegetation phenology between the coastal and inland cities. Differences in temperature and precipitation between coastal and inland cities are crucial factors that affect vegetation phenology $[26,49,50]$. Based on previous research, an increase in temperature in spring can lead to an earlier SOS, whereas an increase in temperature in autumn 

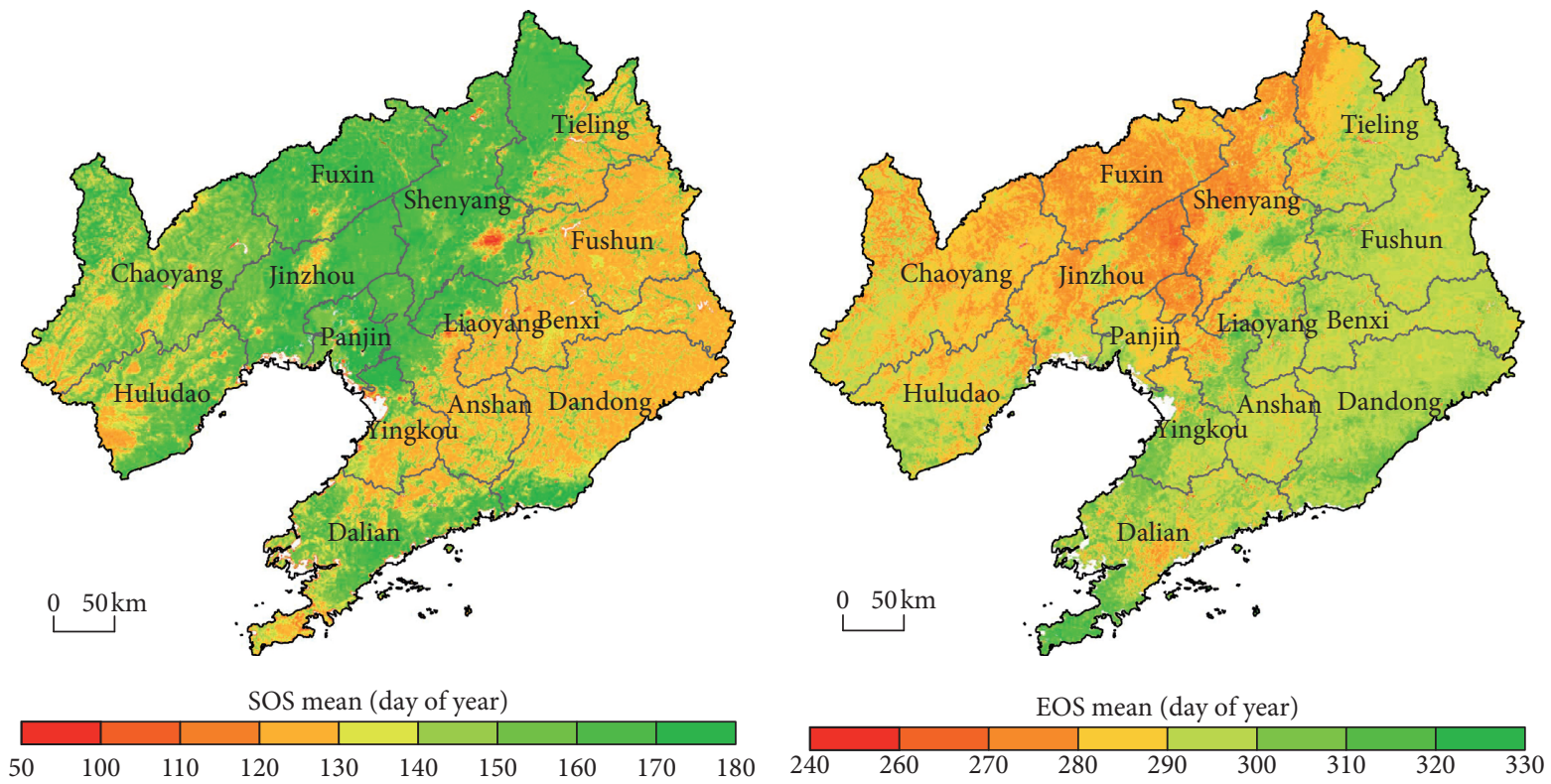

(a)

(b)

Figure 3: Spatial patterns of the average vegetation phenology in Liaoning Province for 2001, 2005, 2010, 2015, and 2018. (a) Average SOS in Liaonian Province between 2001 and 2018. (b) Average EOS in Liaonian Province between 2001 and 2018.

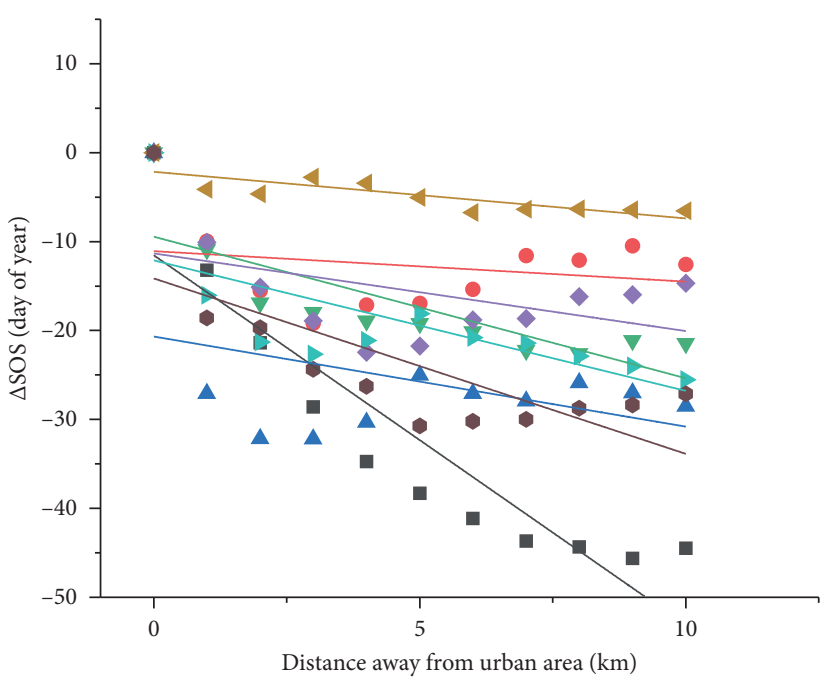

- Shenyang: slope $=-4.16 \pm 0.60, \quad$ Anshan: slope $=-0.34 \pm 0.51$, $r^{2}=0.82$;

$\Delta$ Tieling: slope $=-1.01 \pm 0.82$, $r^{2}=0.05$;

Fushun: slope $=-0.87 \pm 0.56$, $r^{2}=0.13$;

1) Liaoyang: slope $=-1.47 \pm 0.50$, $r^{2}=0.43$;

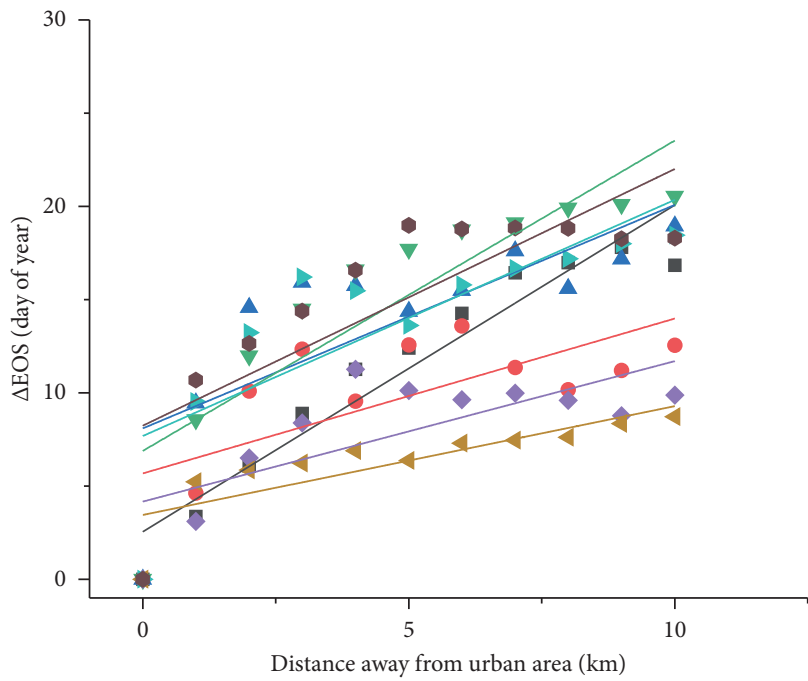

- Shenyang: slope $=1.75 \pm 0.17$, Anshan: slope $=0.83 \pm 0.30$, $r^{2}=0.92$

A Tieling: slope $=1.20 \pm 0.35$, $r^{2}=0.52$

Fushun: slope $=0.75 \pm 0.24$ $r^{2}=0.52$

Liaoyang: slope $=1.27 \pm 0.32$, $r^{2}=0.59$
Anshan: slope $=0.83 \pm 0.30$
$r^{2}=0.40$

$\nabla$ Chaoyang: slope $=1.68 \pm 0.30$, $r^{2}=0.75$

Benxi: slope $=-0.58 \pm 0.13$, $r^{2}=0.64$

- Fuxin: slope $=1.38 \pm 0.35$, $r^{2}=0.58$

(a)

(b)

Figure 4: Continued. 


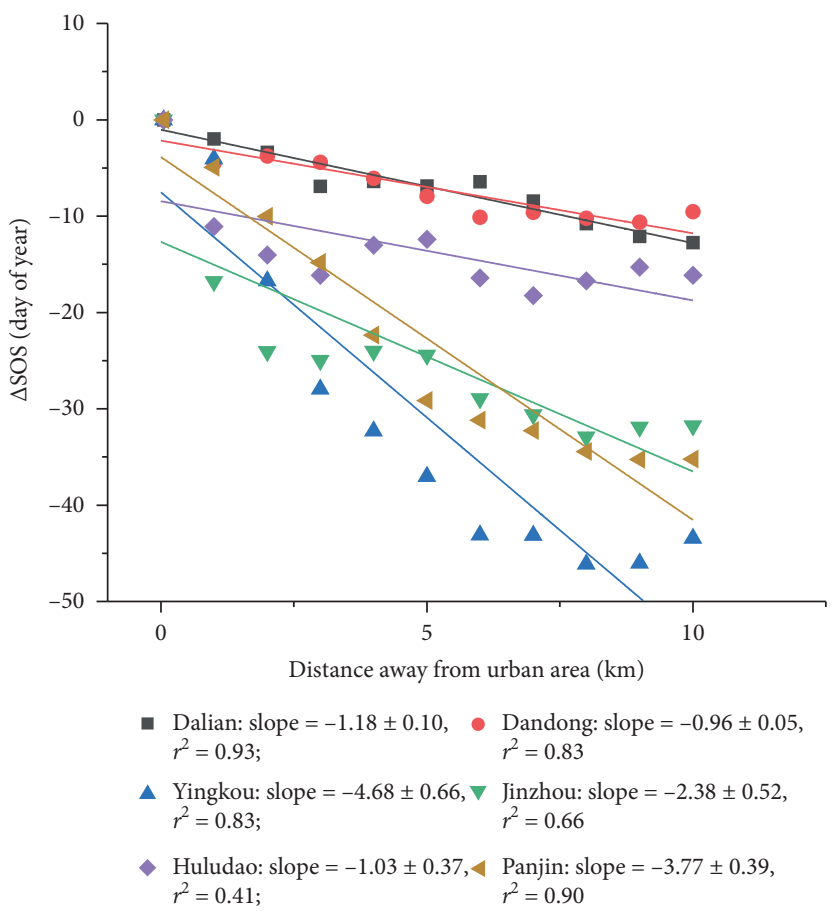

(c)

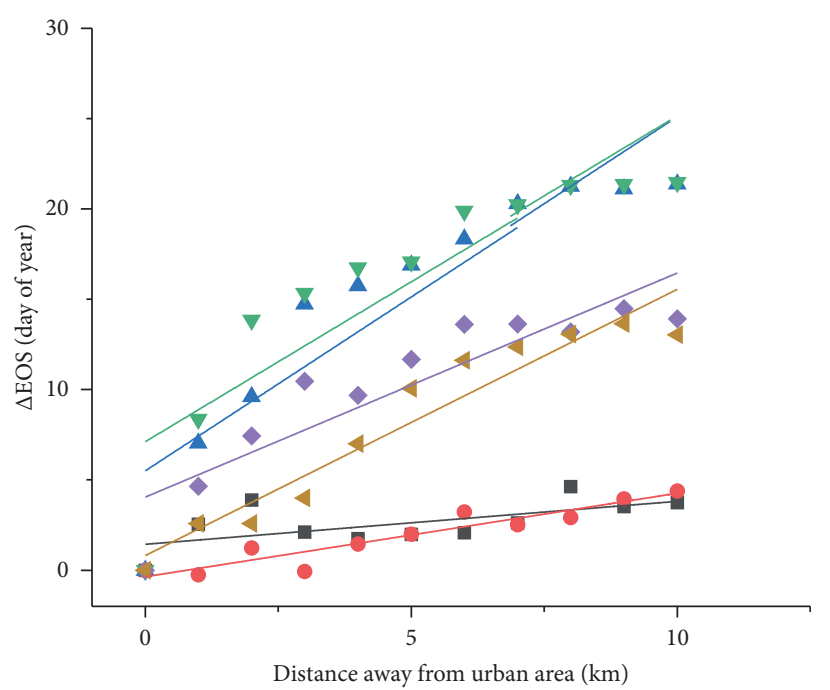

Dalian: slope $=0.24+0.10$ $r^{2}=0.31$

Dandong: slope $=0.46 \pm 0.05$ $r^{2}=0.88$

Yingkou: slope $=1.93 \pm 0.27$, $r^{2}=0.84$

$\nabla$ Jinzhou: slope $=1.77 \pm 0.31$, $r^{2}=0.76$

Huludao: slope $=1.24 \pm 0.20, \quad \varangle$ Panjin: slope $=1.47 \pm 0.14$, $r^{2}=0.79$;

(d)

FIGURE 4: Differences in vegetation phenology along the urban-rural gradients. (a) $\Delta \mathrm{SOS}$ in inland cities. (b) $\Delta \mathrm{EOS}$ in inland cities. (c) $\Delta \mathrm{SOS}$ in coastal cities. (d) $\triangle \mathrm{EOS}$ in coastal cities.

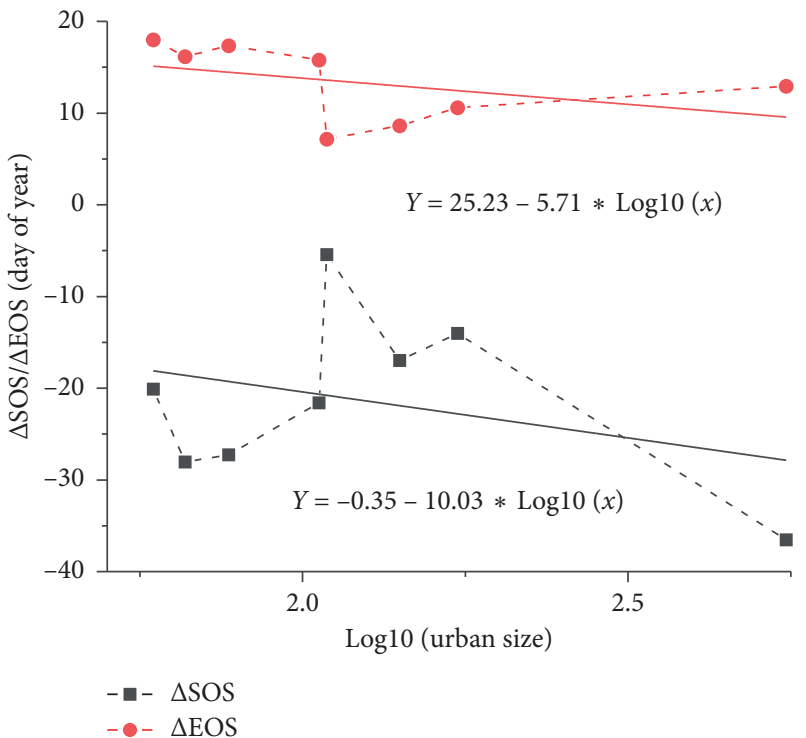

(a)

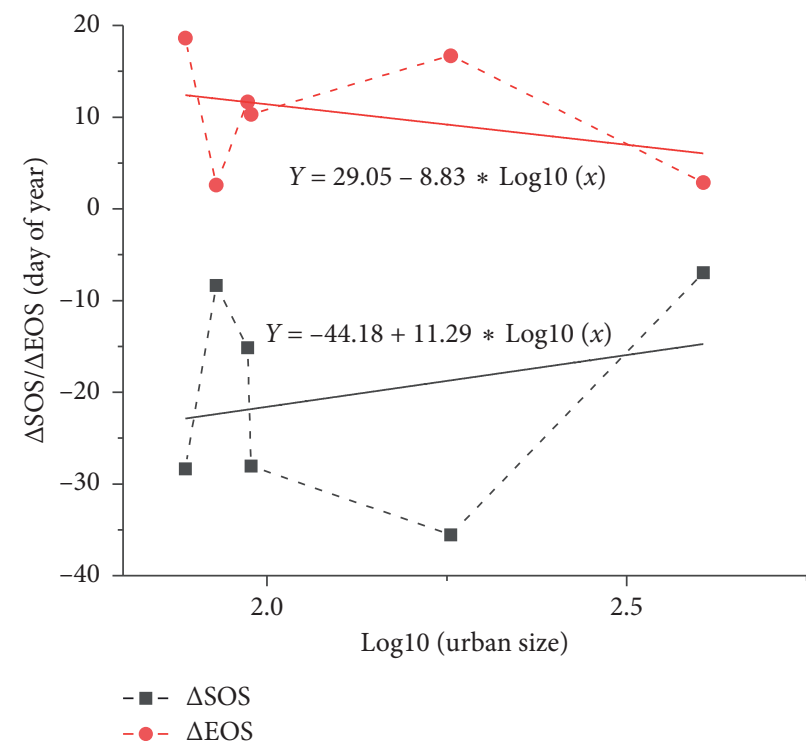

(b)

Figure 5: The relationship between vegetation phenology and urban size. (a) Inland cities. (b) Coastal cities.

can lead to a later EOS. The precipitation gradient also affects the vegetation phenology, but there is an evident lag effect $[45,51,52]$. Compared with inland cities, coastal cities had higher temperatures and more precipitation, which could have led to the differences in vegetation phenology. With continued urbanization, the types of urban land use have changed appreciably, thus resulting in an increase in the area of impervious surfaces [53]. Other studies have found that there is an evident correlation between vegetation phenology and urbanization (i.e., urbanization leads to an earlier SOS and later EOS), and the magnitude of urbanization (i.e., the area of impervious 


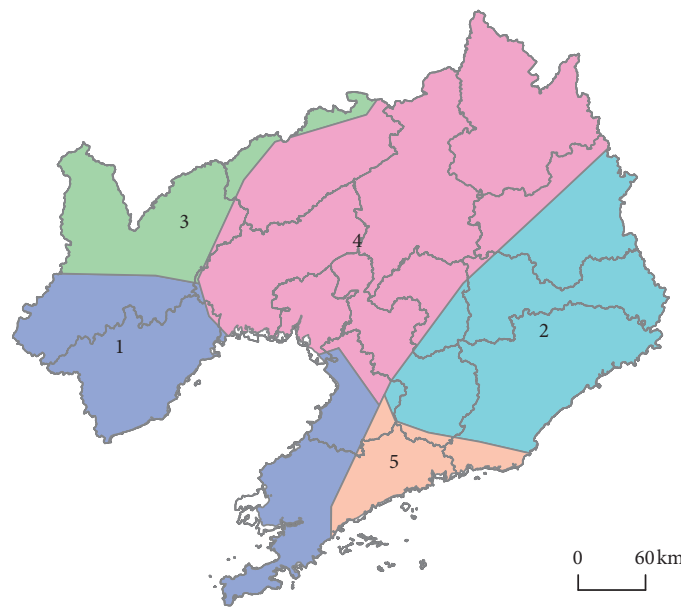

Climate zone

1: Hebei region in south temperate zone (SOS: 144.31 days, EOS: 293.14 days)

2: Sanjiang-Changbai region in middle temperate zone (SOS: 131.07 days, EOS: 294.84 days)

$\square$ 3: Mengdong region in middle temperate zone (SOS: 154.72 days, EOS: 283.65 days)

4: Songliao region in region in middle temperate zone (SOS: 156.20 days, EOS: 286.93 days)

5: Liaodong-Jiaodong Peninsula region in south temperate zone (SOS: 149.81 days, EOS: 294.38 days)

(a)

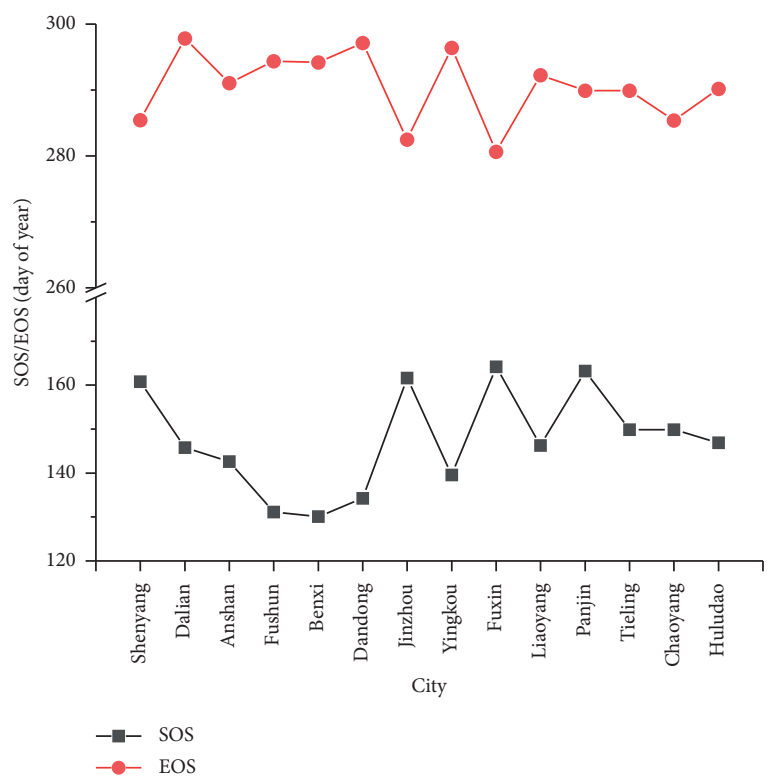

(b)

Figure 6: (a) Climate zone of Liaoning Province and (b) Vegetation phenology of 14 cities in Liaoning Province.

Table 3: Phenology of different land use types.

\begin{tabular}{|c|c|c|c|c|c|c|c|c|c|}
\hline \multirow{2}{*}{$\begin{array}{l}\text { Land use } \\
\text { types } \\
\text { Name }\end{array}$} & \multicolumn{2}{|c|}{ Agricultural land } & \multicolumn{4}{|c|}{ Forestland } & \multicolumn{3}{|c|}{ Grassland } \\
\hline & $\begin{array}{l}\text { Paddy } \\
\text { field }\end{array}$ & $\begin{array}{l}\text { Dry } \\
\text { land }\end{array}$ & Woodland & $\begin{array}{l}\text { Shrub } \\
\text { land }\end{array}$ & $\begin{array}{c}\text { Sparse } \\
\text { woodland }\end{array}$ & $\begin{array}{c}\text { Other } \\
\text { woodlands }\end{array}$ & $\begin{array}{l}\text { High-cover } \\
\text { grassland }\end{array}$ & $\begin{array}{l}\text { Midcover } \\
\text { grassland }\end{array}$ & $\begin{array}{c}\text { Low-cover } \\
\text { grassland }\end{array}$ \\
\hline $\begin{array}{l}\text { SOS (day of } \\
\text { year) }\end{array}$ & 165.63 & 156.03 & 134.22 & 146.54 & 147.62 & 152.65 & 152.07 & 152.09 & 153.71 \\
\hline $\begin{array}{l}\text { EOS (day of } \\
\text { year) }\end{array}$ & 288.89 & 286.52 & 293.93 & 289.11 & 288.74 & 293.44 & 286.36 & 285.24 & 284.22 \\
\hline
\end{tabular}

surfaces) has a significant relationship with the advanced SOS and delayed EOS [54-56]; this is consistent with the results of this study. Considering the differences in climate between the coastal and inland cities, we used the urban built-up areas to represent urban size and investigated the difference in vegetation phenology between urban and rural areas with respect to various urban sizes. The results differed, to a certain extent, from those reported in [33], and the data were closely related to the study area, data, methods, and period $[57,58]$.

4.2. Uncertainties. This study explored the response patterns of vegetation phenology along urban-rural gradients for different sized urban areas in coastal and inland cities, and the results provide a basis for forecasting the influence that urbanization has on the ecological environment. Nevertheless, this study had the following limitations: (1) use of MOD13Q1 to obtain the vegetation phenology affected the accuracy of vegetation phenology results due to the occurrence of mixed pixels in the data product [59] and (2) because of the abnormal fluctuations and discontinuity of the DN pixel values, there was a certain subjectivity when using nighttime light data to obtain the range of urban built-up areas based on the threshold iterative method, which affected the accuracy [41, 60].

Future studies should consider the comprehensive effects of climate background, geographical location, and urbanization on vegetation phenology. Furthermore, higher-resolution remote sensing data products should be applied in order to more realistically reflect the response of vegetation phenology to urbanization, so that the impact of urbanization on the ecological environment can be quantified.

\section{Conclusions}

This study used Liaoning Province in China as the research subject. With MODIS EVI time series data from 2001, 2005, 2010, 2015, and 2018, as well as multisource data such as 
nighttime light data and China City Statistical Yearbook data, we classified urban built-up areas into different urban sizes and investigated the differences in the vegetation phenology along urban-rural gradients in variously sized urban areas between coastal and inland cities. Based on these analyses, our conclusions indicate the following:

(1) The urban built-up areas iteratively extracted by using the threshold method based on the nighttime light data included various land use types. There was apparent continuity among the various types, with an error rate below $7 \%$.

(2) The SOS of Liaoning Province occurred during days 100-180, while the EOS occurred during days 260-330. The difference in the SOS between the coastal and inland cities was insignificant (1.70 days), but that for the EOS was significant (4.47 days).

(3) In contrast with rural areas, urban areas had an earlier SOS and later EOS. Differences in the SOS and EOS along the urban-rural gradients of coastal cities were smaller than those of the inland cities, with a difference of 0.85 and 2.85 days, respectively. In the differently sized urban areas, the $\triangle \mathrm{SOS}$ and $\triangle \mathrm{EOS}$ of inland cities had negative correlations with the urban size. The $\triangle \mathrm{SOS}$ and $\triangle \mathrm{EOS}$ of coastal cities showed a positive and negative correlation with the urban size, respectively.

Our study provides a reference for quantifying the influence that urbanization has on vegetation phenology. Moreover, a comparative study on the differences in vegetation phenology along urban-rural gradients between coastal and inland cities facilitates our understanding of different urbanization processes in coastal and inland cities, which is vital for improvements to the ecological environment.

\section{Data Availability}

The data used to support the findings of this study are available from the corresponding author upon request.

\section{Conflicts of Interest}

The authors declare that they have no conflicts of interest.

\section{Acknowledgments}

This research was supported by the National Natural Science Foundation of China (grant nos. 41771178, 41630749, and 41471140), the Program for Liaoning Innovative Talents in University (grant no. LR2017017), and the Liaoning Province Outstanding Youth Program (grant no. LJQ2015058). The authors would like to thank all consulting experts for their comments on the phenological extraction.

\section{References}

[1] A. D. Richardson, T. F. Keenan, M. Migliavacca, Y. Ryu, O. Sonnentag, and M. Toomey, "Climate change, phenology, and phenological control of vegetation feedbacks to the climate system," Agricultural and Forest Meteorology, vol. 169, pp. 156-173, 2013.

[2] L. Wang, H. Chen, Q. Li, and W. Yu, "Research advances in plant phenology and climate," Acta Ecologica Sinica, vol. 30, no. 2, pp. 447-454, 2010.

[3] J. Zheng, Q. Ge, and Z. Hao, "Effect of climate warming on plant phenology change in China in last 40 years," Chinese Science Bulletin, vol. 47, no. 20, pp. 1582-1587, 2002.

[4] J. Yang, W. Liu, Y. Li, X. Li, and Q. Ge, "Simulating intraurban land use dynamics under multiple scenarios based on fuzzy cellular automata: a case study of Jinzhou District, Dalian," Complexity, vol. 2018, Article ID 7202985, 17 pages, 2018.

[5] Y. Yao, Z. Liang, Z. Yuan et al., "A human-machine adversarial scoring framework for urban perception assessment using street-view images," International Journal of Geographical Information Science, vol. 33, no. 12, pp. 2363-2384, 2019.

[6] Y. Yao, X. Liu, X. Li et al., "Simulating urban land-use changes at a large scale by integrating dynamic land parcel subdivision and vector-based cellular automata," International Journal of Geographical Information Science, vol. 31, no. 12, pp. 24522479, 2017.

[7] K. Eugenia and C. Ming, "Impact of urbanization and landuse change on climate," Letters to Nature, vol. 423, pp. 528$531,2003$.

[8] I. Martínez-Zarzoso and A. Maruotti, "The impact of urbanization on $\mathrm{CO}_{2}$ emissions: evidence from developing countries," Ecological Economics, vol. 70, no. 7, pp. 1344-1353, 2011.

[9] M. L. McKinney, "Urbanization as a major cause of biotic homogenization," Biological Conservation, vol. 127, no. 3, pp. 247-260, 2006.

[10] M. L. McKinney, "Effects of urbanization on species richness: a review of plants and animals," Urban Ecosystems, vol. 11, no. 2, pp. 161-176, 2008.

[11] S. Muhammad, X. Long, M. Salman, and L. Dauda, "Effect of urbanization and international trade on $\mathrm{CO}_{2}$ emissions across 65 belt and road initiative countries," Energy, vol. 196, 2020.

[12] Z. Wu, Q. Zhang, C. Song et al., "Impacts of urbanization on spatio-temporal variations of temperature over the Pearl River Delta," Acta Geographica Sinica, vol. 74, no. 11, pp. 23422357, 2019.

[13] J. Yang, J. Sun, Q. Ge, and X. Li, “Assessing the impacts of urbanization-associated green space on urban land surface temperature: a case study of Dalian, China," Urban Forestry \& Urban Greening, vol. 22, pp. 1-10, 2017.

[14] K. Yang, Y. Luo, K. Chen et al., "Spatial-temporal variations in urbanization in Kunming and their impact on urban lake water quality," Land Degradation \& Development, 2020.

[15] P. Xie, J. Yang, H. Wang, Y. Liu, and Y. Liu, "A New method of simulating urban ventilation corridors using circuit theory," Sustainable Cities and Society, vol. 59, p. 102162, 2020.

[16] X. Zhang, Q. Ge, and J. Zheng, "Overview on the vegetation phenology using the remote sensing," Advance in Earth Sciences, vol. 18, no. 4, pp. 534-544, 2003.

[17] F. Huang, X. Mo, Z. Lin, and S. Hu, "Dynamics and responses of vegetation to climatic variations in Ziya-Daqing basins, China," Chinese Geographical Science, vol. 26, no. 4, pp. 478-494, 2016.

[18] J. Yuan, Z. Niu, and C. Wang, "Vegetation NPP distribution based on MODIS data and CASA model-A case study of northern Hebei Province," Chinese Geographical Science, vol. 16, no. 4, pp. 334-341, 2006. 
[19] W. Jia, Z. Zhao, J. Zu, J. Chen, J. Wang, and D. Ding, "Phenological variation in different vegetation types and their response to climate change in the Qilian Mountains, China, 1982-2014," Acta Ecologica Sinica, vol. 36, no. 23, pp. 7826-7840, 2016.

[20] R. Wu, Y. Hong, and G. Bao, "The change of vegetation phenology and its impacts on vegetation productivity in Inner Mongolia during 2001-2016," Acta Agrestia Sinica, vol. 27, no. 6, pp. 1685-1693, 2019.

[21] R. Yao, L. Wang, X. Huang, X. Guo, Z. Niu, and H. Liu, "Investigation of urbanization effects on land surface phenology in northeast China during 2001-2015," Remote Sensing, vol. 9, no. 1, p. 66, 2017.

[22] J. Zhao, Y. Wang, Z. Zhang et al., "The variations of land surface phenology in Northeast China and its responses to climate change from 1982 to 2013," Remote Sensing, vol. 8, no. 400, pp. 1-23, 2016.

[23] X. Zhang, M. A. Friedl, C. B. Schaaf, A. H. Strahler, and A. Schneider, "The footprint of urban climates on vegetation phenology," Geophysical Research Letters, vol. 31, no. 12, pp. 1133-1145, 2004.

[24] D. Zhou, S. Zhao, L. Zhang, and S. Liu, "Remotely sensed assessment of urbanization effects on vegetation phenology in China's 32 major cities," Remote Sensing of Environment, vol. 176, pp. 272-281, 2016.

[25] S. Liang, P. Shi, and H. Li, "Urban spring phenology in the middle temperate zone of China: dynamics and influence factors," International Journal of Biometeorology, vol. 60, no. 4, pp. 531-544, 2016.

[26] Q. Liu, Y. H. Fu, Z. Zeng, M. Huang, X. Li, and S. Piao, "Temperature, precipitation, and insolation effects on autumn vegetation phenology in temperate China," Global Change Biology, vol. 22, no. 2, pp. 644-655, 2016.

[27] L. Guo, J. Dai, M. Wang, J. Xu, and E. Luedeling, "Responses of spring phenology in temperate zone trees to climate warming: a case study of apricot flowering in China," Agricultural and Forest Meteorology, vol. 201, pp. 1-7, 2015.

[28] N. Delpierre, Y. Vitasse, I. Chuine et al., "Temperate and boreal forest tree phenology: from organ-scale processes to terrestrial ecosystem models," Annals of Forest Science, vol. 73, no. 1, pp. 5-25, 2016.

[29] J. Zhao, H. Zhang, Z. Zhang, X. Guo, X. Li, and C. Chen, "Spatial and temporal changes in vegetation phenology at middle and high latitudes of the Northern Hemisphere over the past three decades," Remote Sensing, vol. 7, no. 8, pp. 10973-10995, 2015.

[30] Y. Wei, W. Song, C. Xiu, and Z. Zhao, "The rich-club phenomenon of China's population flow network during the country's spring festival," Applied Geography, vol. 96, pp. 77-85, 2018.

[31] W. Lv and C. Diao, "Research on the type of city-size distribution in China based on urban built-up area," Journal of Southwest University, vol. 35, no. 9, pp. 138-144, 2013.

[32] M. Tan and C. Lu, "Distribution of China city size expreessed by urban built-up area," Acta Geographica Sinica, vol. 58, no. 2, pp. 285-293, 2003.

[33] X. Li, Y. Zhou, G. R. Asrar, J. Mao, X. Li, and W. Li, "Response of vegetation phenology to urbanization in the conterminous United States," Global Change Biology, vol. 23, no. 7, pp. 2818-2830, 2016.

[34] X. Li, D. Li, H. Xu, and C. Wu, "Intercalibration between DMSP/OLS and VIIRS night-time light images to evaluate city light dynamics of Syria's major human settlement during
Syrian Civil War," International Journal of Remote Sensing, vol. 38, no. 21, pp. 1-18, 2017.

[35] G. Shi, N. Jiang, Y. Li, and B. He, "Analysis of the dynamic urban expansion based on multi-sourced data from 1998 to 2013: a case study of Jiangsu Province," Sustainability, vol. 10, no. 10, p. 3467, 2018.

[36] Y. Zhou, Y. Chen, Y. Liu, F. Tian, and X. Yi, "Generation and verification of NPP-VIIRS annual nighttime light data," Remote Sensing Information, vol. 34, no. 2, pp. 62-68, 2019.

[37] R. Cao, Y. Chen, M. Shen et al., "A simple method to improve the quality of NDVI time-series data by integrating spatiotemporal information with the Savitzky-Golay filter," Remote Sensing of Environment, vol. 217, pp. 244-257, 2018.

[38] B. Tan, J. T. Morisette, R. E. Wolfe et al., "An enhanced TIMESAT algorithm for estimating vegetation phenology metrics from MODIS data," IEEE Journal of Selected Topics in Applied Earth Observations and Remote Sensing, vol. 4, no. 2, pp. 361-371, 2011.

[39] N. Cong, S. Piao, A. Chen et al., "Spring vegetation green-up date in China inferred from SPOT NDVI data: a multiple model analysis," Agricultural and Forest Meteorology, vol. 165, pp. 104-113, 2012.

[40] M. A. White, K. M. de BEURS, K. Didan et al., "Intercomparison, interpretation, and assessment of spring phenology in North America estimated from remote sensing for 1982-2006," Global Change Biology, vol. 15, no. 10, pp. 2335-2359, 2009.

[41] Z. Lin, H. Xu, and S. Huang, "Monitoring of the urban expansion dynamics in China's East Coast using DMSP/OLS nighttime light imagery," Journal of Geo-Information Science, vol. 21, no. 7, pp. 1074-1085, 2019.

[42] K. Shi, C. Huang, B. Yu, B. Yin, Y. Huang, and J. Wu, "Evaluation of NPP-VIIRS night-time light composite data for extracting built-up urban areas," Remote Sensing Letters, vol. 5, no. 4, pp. 358-366, 2014.

[43] C. Jeganathan, J. Dash, and P. M. Atkinson, "Remotely sensed trends in the phenology of northern high latitude terrestrial vegetation, controlling for land cover change and vegetation type," Remote Sensing of Environment, vol. 143, pp. 154-170, 2014.

[44] I. D. Stewart and T. R. Oke, "Local climate zones for urban temperature studies," Bulletin of the American Meteorological Society, vol. 93, no. 12, pp. 1879-1900, 2012.

[45] J. Du, Z. He, K. B. Piatek, L. Chen, P. Lin, and X. Zhu, "Interacting effects of temperature and precipitation on climatic sensitivity of spring vegetation green-up in arid mountains of China," Agricultural and Forest Meteorology, vol. 269-270, pp. 71-77, 2019.

[46] J. Yang, S. Jin, X. Xiao et al., "Local climate zone ventilation and urban land surface temperatures: towards a performancebased and wind-sensitive planning proposal in megacities," Sustainable Cities and Society, vol. 47, p. 101487, 2019.

[47] J. Zu, Y. Zhang, K. Huang, Y. Liu, N. Chen, and N. Cong, "Biological and climate factors co-regulated spatial-temporal dynamics of vegetation autumn phenology on the Tibetan Plateau," International Journal of Applied Earth Observation and Geoinformation, vol. 69, pp. 198-205, 2018.

[48] Z. Li, H. Tang, P. Yang et al., "Responses of cropland phenophases to agricultural thermal resources change in Northeast China," Acta Geographica Sinica, vol. 66, no. 7, pp. 928-939, 2011.

[49] X. Wang, Q. Gao, C. Wang, and M. Yu, "Spatiotemporal patterns of vegetation phenology change and relationships 
with climate in the two transects of East China," Global Ecology and Conservation, vol. 10, pp. 206-219, 2017.

[50] H. Wang, D. Tetzlaff, J. Buttle et al., "Climate-phenologyhydrology interactions in northern high latitudes: assessing the value of remote sensing data in catchment ecohydrological studies," Science of the Total Environment, vol. 656, pp. 19-28, 2019.

[51] D. C. Sohoulande Djebou, V. P. Singh, and O. W. Frauenfeld, "Vegetation response to precipitation across the aridity gradient of the southwestern United States," Journal of Arid Environments, vol. 115, pp. 35-43, 2015.

[52] T. G. Workie and H. J. Debella, "Climate change and its effects on vegetation phenology across ecoregions of Ethiopia," Global Ecology and Conservation, vol. 13, pp. 1-13, 2018.

[53] K. Yang, M. Pan, Y. Luo, K. Chen, Y. Zhao, and X. Zhou, "A time-series analysis of urbanization-induced impervious surface area extent in the Dianchi Lake watershed from 1988-2017," International Journal of Remote Sensing, vol. 40, no. 2, pp. 573-592, 2019.

[54] T. Qiu, C. Song, Y. Zhang, H. Liu, and J. M. Vose, "Urbanization and climate change jointly shift land surface phenology in the northern mid-latitude large cities," Remote Sensing of Environment, vol. 236, p. 111477, 2020.

[55] Q. Ren, C. He, Q. Huang, and Y. Zhou, "Urbanization impacts on vegetation phenology in China," Remote Sensing, vol. 10, no. 12, pp. 1-16, 2018.

[56] S. C. Zipper, J. Schatz, A. Singh, C. J. Kucharik, P. A. Townsend, and S. P. Loheide, "Urban heat island impacts on plant phenology: intra-urban variability and response to land cover," Environmental Research Letters, vol. 11, no. 5, pp. 1-12, 2016.

[57] Q. Liu, Y. H. Fu, Y. Liu, I. A. Janssens, and S. Piao, "Simulating the onset of spring vegetation growth across the Northern Hemisphere," Global Change Biology, vol. 24, no. 3, pp. 1342-1356, 2017.

[58] X. Shen, B. Liu, Z. Xue, M. Jiang, X. Lu, and Q. Zhang, "Spatiotemporal variation in vegetation spring phenology and its response to climate change in freshwater marshes of Northeast China," Science of the Total Environment, vol. 666, pp. 1169-1177, 2019.

[59] X. Chen, D. Wang, J. Chen, C. Wang, and M. Shen, "The mixed pixel effect in land surface phenology: a simulation study," Remote Sensing of Environment, vol. 211, pp. 338-344, 2018.

[60] S. Shu, B. Yu, J. Wu, and H. Liu, "Methods for deriving urban built-up area using night-light data: assessment and application," Remote Sensing Technology and Application, vol. 26, no. 2, pp. 169-176, 2011. 